On an Apparatus to illustrate the Interference of two Plane Waves

This content has been downloaded from IOPscience. Please scroll down to see the full text. 1875 Proc. Phys. Soc. London 2182

(http://iopscience.iop.org/1478-7814/2/1/317)

View the table of contents for this issue, or go to the journal homepage for more

Download details:

IP Address: 137.149.200.5

This content was downloaded on 02/10/2015 at 08:17

Please note that terms and conditions apply. 
is solid, and perhaps also changes very little while the dielectric (water) is liquid. It must therefore probably undergo a great change at the melting-point, since we have shown that the specific inductive capacity of water at $8^{0.7} \mathrm{C}$. is about 2240 times that of ice at $-13^{\circ} .5 \mathrm{C}$. The specific inductive capacity seems therefore to be a stress and strain phenomenon, and to be intimately connected with the rigidity of the body; whereas the connexion between conductivity and rigidity seems to be less marked. This, wo think, bears out all recent theories in molecular physics. The complete investigation of the connexion between the conductivity and specific industive calpacity of $\left\{\begin{array}{c}\text { water } \\ \text { ice }\end{array}\right\}$ at different temperatures will form the subject of a second paper.

March 22, 1877.

\section{On an Apparatus to illustrate the Interference of two} Plane Waves. By C. J. Woodward, B.Sc.

THE effect produced by the simultaneous propagation of two or more plane waves is in a few simple cases easily realized; in others, however, the mind is somewhat harassed in ascertaining what will be the resultant wave made up of certain given elements. The apparatus I am about to describe is intended to assist the student by enabling him to draw for himself the required resultant wave ; or the apparatus may be used in the class-room to illustrate the general subject of interference.

So far as I know, the only apparatus of the kind in use by lecturers is one based on the method described by Dr. Young (Natural Philosophy, Lecture xxxiii.); but here, to obtain any variety of effects, a series of dissected waves are required, and these are troublesome to make or expensive to purchase; whereas with the arrangement I now exhibit to the Society, when once the framework of the apparatus is made, combinations of any desired waves may be drawn, with merely the trouble incidental to cutting out the required waves in cardboard or thin tin.

The apparatus consists of a board, A A, about 3 feet long, 
2 feet wide, and 1 inch thick, set upright on a base-board $B$. A strip of cardboard, C, is fastened by drawing-pins to the board; and on this is drawn the compound wave resulting from the two component waves $\mathrm{W}, \mathrm{W}^{\prime}$. These component waves are cut out of strong cardboard or tin, and can be easily and quickly placed in position by letting down the flaps $F, F^{\prime}$. $\mathrm{D}$ is a stout mahogany board, with a wedge-shaped groove in

Fig. 1.

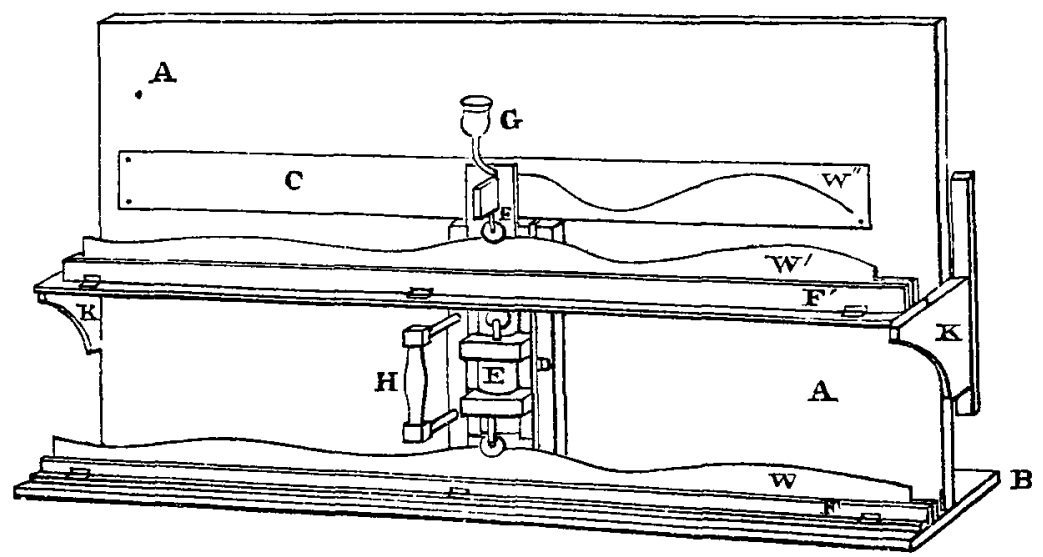

Moving the boards D, E, F from right to left by means of the handle $H$ traces the wave $W^{\prime \prime}$, a combination of the waves $W$ and $W^{\prime}$.

it sufficiently wide to allow the board $E$ to slide freely up and down. A handle, $\mathrm{H}$, is secured to the board $\mathrm{D}$ to enable the operator to move $\mathrm{D}$ from one end of $\mathrm{A}$ to the other. The board $\mathrm{E}$ has a pulley fastened to its lower part; and this pulley runs on the tin wave $W$, so that if the board $D$ be moved horizontally, the sliding board $\mathrm{E}$ will rise and fall as the pulley passes over $W$; and of course, were there a pencil attached directly to $\mathrm{E}$, the pencil would trace a curve the same, or very nearly the same, as that of the wave. The sliding board $\mathrm{E}$ has also a wedge-shaped groove cut in it to allow the board $\mathrm{F}$ to slide vertically; and to $\mathrm{F}$ is also attached a pulley, which runs on the wave $W^{\prime}$. With the upper board $F$, as with the lower, if the pulley be made to traverse the wave $W^{\prime}$, a pencil fastened to $F$ would trace a wave corresponding to $W^{\prime}$. The pencil (or, more properly, pen) used in the apparatus consists of a thistle-funnel, with the tube drawn out so as to have an 
opening of only a fraction of a millimetre. The tube is bent as shown in the figure at $G$; and the drawn-out part presses gently against the cardboard C. To charge the pen, some violet ink is poured into the thistle-funnel, which is then closed with a cork.

The action of the apparatus will easily be understood. As the board D moves along, the board E rises and falls; and this by means of a roller causes the wave $W^{\prime}$ to rise and fall to each elevation and depression of the wave $W$ below. Now the board $\mathrm{D}$ as it moves along carries with it the sliding board $\mathrm{F}$ with the attached pencil ; and as this board $\mathrm{F}$ is carried along it rises and falls to the elevations and depressions of the wave $W^{\prime}$. But, as has been said, it also rises and falls to the wave $W$ : the motion of the pencil is therefore the algebraic sum of the forms of waves $W$ and $W^{\prime}$. In the figure Fig. 2.

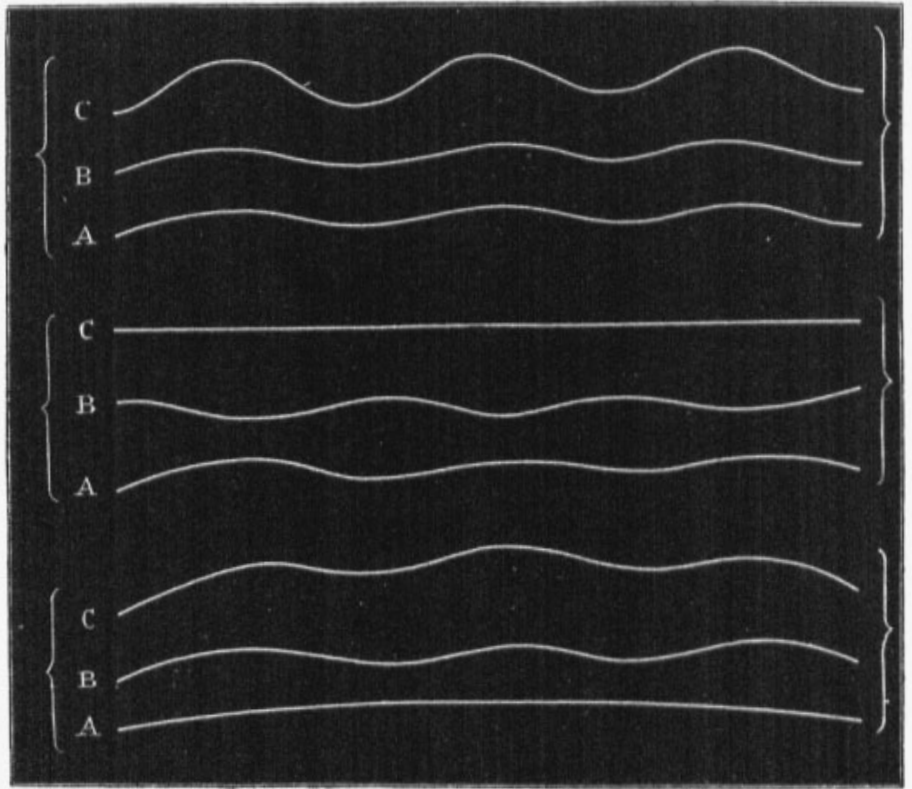

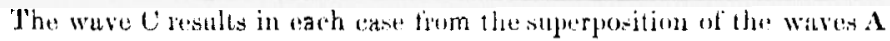
and $\mathrm{B}$ immediately below $\mathrm{C}$.

the waves $W$ and $W^{\prime}$ are of the same length and amplitude and correspond in phase, so that the tracing $W^{\prime \prime}$ is a wave of the same length but twice the amplitude of the waves below. 
By moving the wave $\mathrm{W}^{\prime}$ to the right, its phase may be made $\frac{1}{4}, \frac{1}{2}$, \&c. of an undulation different, and a fresh tracing obtained. By removing the wave $W^{\prime}$ and inserting successively others of different lengths and amplitudes, various combined waves are traced out on moving the board D along. A few tracings obtained by the apparatus are represented in tig. 2, page 184 .

In order that the frame carrying the wave $\mathrm{W}^{\prime}$ may rise and fall freely, the brackets $\mathrm{K}, \mathrm{K}$ are linked together at the back of the board by a parallel motion, used in the Cowper printingmachine, and which will be found deseribed in Goodeve's 'Elements of Mechanism,' 3rd edit. page 66.

It is obrious that by an extension of the same principle an apparatus could be made to give the tracing of a combination of three or more waves. To do this, however, the mechanical arrangements must be much better than in the comparatively rough instrument $I$ have exhibited.

\section{On Interference Fringes within the Nicol Prism.}

\section{$B y$ Silvanus P. Thompson, B.Sc., B.A.*}

1. Is the 'Edinburgh New Philosophical Journal' for 1828 (p. 23) is a communication "On a Method of so far increasing the divergency of the two Rays in Calcareous Spar that only one Image may be seen at a time." In this, the original account by the inventor of the now well-known Nicol prism, occurs the following sentence:- - "There is a tinge of blue where the ordinary ray vanishes on one side, and a tinge of orange accompanied by a number of obscurely coloured fringes, where it terminates on the other." Probably the great majority of those who are familiar with the Nicol prism are acquainted with the phenomena alluded to in the passage quoted. As the author has not found, however, any more explicit reference to them, nor any attempted explanation of them, he ventures to offer the following account of an examination he has made of their nature and origin.

* Read June 9, 1877. 